\title{
Pseudomonas aeruginosa alginate is refractory to Th1 immune response and impedes host immune clearance in a mouse model of acute lung infection
}

\author{
Zhijun Song, ${ }^{1,2}$ Hong Wu, ${ }^{2}$ Oana Ciofu, ${ }^{2}$ Kok-Fai Kong, ${ }^{1}$ Niels Høiby, ${ }^{2}$ \\ Jørgen Rygaard, ${ }^{3}$ Arsalan Kharazmi $^{2}$ and Kalai Mathee ${ }^{1,2}$ \\ ${ }^{1}$ Department of Biological Sciences, Florida International University, Miami, FL 33199, USA \\ ${ }^{2}$ Department of Clinical Microbiology, Rigshospitalet, Copenhagen, Denmark \\ ${ }^{3}$ Bartholin Institute, Kommunehospitalet, Copenhagen, Denmark
}

\begin{abstract}
Pseudomonas aeruginosa is an opportunistic respiratory pathogen that accounts for most of the morbidity and mortality in cystic fibrosis (CF) patients. In CF-affected lungs, the bacteria undergo conversion from a non-mucoid to a non-tractable mucoid phenotype, due to overproduction of alginate. The effect of alginate production on pathogenicity was investigated by using an acute lung infection mouse model that compared a non-mucoid $P$. aeruginosa strain, PAO1, to its constitutive alginate-overproducing derivative, $\mathrm{Alg}^{+} \mathrm{PAOmucA22}$, and an alginate-defective strain, $\mathrm{Alg}^{-}$ $\mathrm{PAO}$ algD. Bacterial suspensions were instilled into the left bronchus and examined 24 and $48 \mathrm{~h}$ post-infection. The highest bacterial loads and the most severe lung pathology were observed with strain $\mathrm{Alg}^{-} \mathrm{PAOalgD}$ at $24 \mathrm{~h}$ post-infection, which may have been due to an increase in expression of bacterial elastase by the mutant. Significantly lower lung and spleen bacterial loads were found in the two non-mucoid (PAO1 and $\mathrm{Alg}^{-} \mathrm{PAOalgD}$ ) groups, compared to the mucoid $\mathrm{Alg}^{+} \mathrm{PAOmucA22}$ group, between 24 and $48 \mathrm{~h}$ post-infection. The positive correlation between lung bacteriology and lung macroscopic pathology in the $\mathrm{Alg}^{+} \mathrm{PAO}$ mucA22 group suggests that alginate production not only impedes pulmonary clearing, but also results in severe lung damage. Positive correlations between IL12 levels and lung macroscopic pathology, and between IL12 and IFN- $\gamma$ levels in the Alg ${ }^{+}$ PAOmucA22 group, suggested a possible contribution of these pro-inflammatory cytokines to tissue damage. No significant differences were found between the three groups in lung cytokine responses at 24 or $48 \mathrm{~h}$ post-infection. However, on comparison within each group at 24 and $48 \mathrm{~h}$ post-infection, a significant increase in the pro-inflammatory cytokine IFN- $\gamma$ was observed. Higher ratios of IFN- $\gamma /$ IL4 and IFN- $\gamma /$ IL10, but lower IL10 levels, were also found in all three groups. These results indicate a Th1-predominated immune response in these animals. Such cytokine responses could have aided the clearance of non-mucoid $P$. aeruginosa, but were not sufficient to alleviate infection by the mucoid variants. Alginate production may promote survival and persistence of this pathogenic micro-organism in the lung.
\end{abstract}

Received 15 November 2002 Accepted 4 April 2003

\section{INTRODUCTION}

Pseudomonas aeruginosa is an opportunistic pathogen of immunocompromised patients and a common cause of chronic lung infection in patients with cystic fibrosis (CF) (Høiby, 1975). The majority (60-90\%) of CF patients are colonized initially by non-mucoid $P$. aeruginosa, but most strains isolated from patients with advanced lung disease have mucoid colony morphology (Høiby et al., 2001). This phenotype is rare among strains that cause other infections

Abbreviations: CF, cystic fibrosis; LIMP, lung index of macroscopic pathology; MN, mononuclear leukocyte; PMN, polymorphonuclear cell.
(Høiby, 1975). Mucoid P. aeruginosa strains appear to have a distinct survival advantage in the CF-affected lung. The mucoid phenotype is due to overproduction of the exopolysaccharide alginate, an $\mathrm{O}$-acetylated linear polymer of Dmannuronate and L-guluronate residues (Davidson et al., 1977). Alginate aids biofilm growth (Lam et al., 1980) and bacterial adherence to human cells and protects bacteria from host defences (Lyczak et al., 2002). The biofilm mode of growth improves bacterial survival in the lung environment, increases resistance to antibiotics and biocides and decreases susceptibility to host defences (Høiby et al., 2001).

Alginate production in vitro can be triggered by nutrient 
starvation, antibiotic treatment, slow growth rate, ethanol dehydration, high osmotic pressure or high ionic strength (Evans \& Linker, 1973; Govan \& Fyfe, 1978; DeVault et al., 1990; Terry et al., 1991). We have demonstrated that local accumulation of activated polymorphonuclear cells (PMNs) exerts selective pressures on the bacteria from phagocytosis and oxygen free radicals, resulting in conversion from the non-mucoid to the mucoid phenotype (Mathee et al., 1999). Approximately $84 \%$ of mucoid CF isolates have mutations in the $m u c A$ gene, which encodes a negative regulator of an alternative sigma factor, AlgT/U (Boucher et al., 1997). MucA interacts directly with $\mathrm{Alg} \mathrm{T} / \mathrm{U}$, inhibiting its activity (Hughes \& Mathee, 1998). On inactivation of MucA, AlgT/U triggers biosynthesis of alginate via a complex regulatory circuit (Mathee et al., 2002). This culminates in activation of the $18 \mathrm{~kb}$ alginate biosynthesis $(\operatorname{alg} D)$ operon (Mathee et al., 2002).

There is a strong humoral immune response against chronic $P$. aeruginosa infection in most CF patients; this is dominated by a T helper type 2 (Th2) immune response (Høiby et al., 2001). This is characterized by production of cytokines IL4, IL5, IL6 and IL10 and antibodies IgG1 and IgE. The Th1 response is associated with an increase in levels of IFN- $\gamma$, IL2, IL12 and IgG2a (Banchereau, 1995; Germann et al., 1995). The pronounced antibody response in CF patients leads to the formation of immune complexes in the lung that activate complement and result in an infiltration of PMNs, which is a hallmark of chronic infection in CF-affected lungs (Baltimore et al., 1989; Høiby et al., 2001). Bronchoalveolar lavage fluid of young CF patients has normal levels of IL10 (Noah et al., 1997), whereas patients with chronic infections have significantly lower levels of this cytokine (Bonfield et al., 1995b). Furthermore, normal epithelial cells produce IL10 constitutively, but epithelial cells from chronically infected CF patients are defective in IL10 production (Bonfield et al., 1995a).

Many animal models have been used successfully to recreate both acute and chronic $P$. aeruginosa infections (Stotland et al., 2000). However, only a few studies have addressed the role of alginate in pulmonary clearance and these have produced conflicting data. The earliest reported study, which used guinea pigs as an animal model of chronic infection, a CF $P$. aeruginosa isolate and genetically undefined nonmucoid strains, concluded that the $\mathrm{Alg}^{+}$phenotype did not selectively impair pulmonary clearing (Blackwood \& Pennington, 1981). In a more recent study that used a neutropenic mouse model, no difference was observed between the wild-type strain PAO1 and the mutant strain $\operatorname{alg} T / U:: \mathrm{Tc}^{\mathrm{R}}$ (Yu et al., 1996). Interestingly, the null mutant showed a reduced mean time of death in the normal C57BL/6 mouse and the endotoxin-resistant $\mathrm{C} 3 \mathrm{H} / \mathrm{HeJ}$ mouse. The authors concluded that inactivation of algT/U resulted in increased virulence (Yu et al., 1996). Another study looked at clearance of $\mathrm{CF}$ isolates from the murine lung in an aerosol infection model with C57BL/6J, BALB/c and DBA/2NHsd mice, using a wild-type strain and a number of isogenic derivatives (Martin et al., 1993; Boucher et al., 1997). In these experi- ments, the $\mathrm{Alg}^{+}$strain survived better in the lungs than the parent non-mucoid strain and the algD mutant (Boucher et al., 1997). Similar results were observed following repeated aerosol exposure of C57BL/6J mice to other PAO1 derivatives (Yu et al., 1998). The increased host survival could not be attributed to an increase in the pro-inflammatory cytokine TNF- $\alpha$ (Boucher et al., 1997; Yu et al., 1998). There was no difference in lung histopathology or in MIP-2 (the equivalent of IL8) between the two groups of animals at either the 4 or $18 \mathrm{~h}$ time-points (Yu et al., 1998).

Although we know much about the organism, regulation of the alginate genes and changes in the patient's immune response from onset of infection to death, no advances have been made in using this information to control $P$. aeruginosa successfully in CF patients. Animal studies clearly support the view that alginate production impedes bacterial clearance and favours their survival in the lungs; however, survival could not be correlated with host immune response. In the current study, we present a detailed analysis of the role of alginate in the pathogenesis of lung infection by using a mouse model, in which we compare the prototype strain of $P$. aeruginosa, $\mathrm{PAO} 1$, with a constitutive alginate-overproducing derivative and an alginate-defective strain.

\section{METHODS}

Animals. Female, 12-week-old NMRI mice (provided by the Panum Institute, University of Copenhagen, Denmark) were used. The animals were divided randomly into three 'bacterial groups' with 30 animals in each group. They were killed 24 and $48 \mathrm{~h}$ after intra-tracheal bacterial infection. All animal experiments were performed under authorization from the National Animal Ethics Committee of Denmark.

Bacterial strains. The prototypic non-mucoid $P$. aeruginosa strain PAO1 (Holloway \& Morgan, 1986) and its isogenic derivatives were used. These derivatives were the mucoid strain $\mathrm{Alg}^{+} \mathrm{PAOmucA2} 2$ (PDO300), which carries the mucA22 allele that results in constitutive production of alginate (Mathee et al., 1999), and PAOalgD, a nonmucoid strain that carries a deletion in algD (Garrett et al., 1999). Strains were cultured in LB broth $\left(1^{-1}: 10 \mathrm{~g}\right.$ tryptone, $5 \mathrm{~g}$ yeast extract and $5 \mathrm{~g} \mathrm{NaCl}$ ) overnight at $37^{\circ} \mathrm{C}$ and bacterial cells were harvested by centrifugation and resuspended in saline to approximately $1.5 \times 10^{8}$ c.f.u. $\mathrm{ml}^{-1}$.

Animal model. Before challenge, all mice were anaesthetized subcutaneously with a 1:1 (v/v) mixture of etomidate (Janssen) and midazolam (Roche) at a dose of $10 \mathrm{ml}$ ( $\mathrm{kg}$ body $\mathrm{wt})^{-1}$ and then tracheotomized (Moser et al., 1997). Each mouse was challenged intratracheally with $0.04 \mathrm{ml}$ bacterial suspension as described previously (Moser et al., 1997). Animals were killed by administering $2 \mathrm{ml} 20 \%$ pentobarbital (DAK) $\mathrm{kg}^{-1}$.

Macroscopic pathology. Lung index of macroscopic pathology (LIMP) was calculated by using the following modified formula: LIMP = lung area with pathological changes divided by area of the whole lung (Song et al., 1998). Changes in lung pathology are consolidation, haemorrhage and oedema. Gross pathological changes were grouped according to severity of inflammation as previously described (Song et al., 1998): I, normal; II, swollen lungs, hyperaemia and small atelectasis $\left(<10 \mathrm{~mm}^{2}\right)$; III, pleural adhesions and atelectasis $\left(<40 \mathrm{~mm}^{2}\right)$; IV, abscesses, large atelectasis and haemorrhages. 
Histopathological scores. Cellular alterations in the lungs were classified as acute or chronic inflammation by a scoring system based on the proportion of neutrophils or PMNs and mononuclear leukocytes (MNs) in the inflammatory foci (Johansen et al., 1993). Acute inflammation was defined as cellular infiltration in which PMNs were predominant $(\geqslant 90 \%)$ with $\leqslant 10 \%$ MNs, whereas chronic inflammation was defined as a prevalence of MNs (MNs $\geqslant 90 \%$; PMNs $\leqslant 10 \%$ ), which included lymphocytes, plasma cells and the presence of granulomas (Johansen et al., 1993). Both macroscopic and histopathological evaluations were performed as a double-blind study.

Lung and spleen bacteriology. Quantitative bacteriological examination was done as described previously (Johansen et al., 1993). In brief, lungs or spleens were removed aseptically from mice and homogenized in $5 \mathrm{ml}$ PBS. Serially diluted samples were plated onto LB agar plates to determine bacterial count (c.f.u.). The remaining lung homogenate was centrifuged and the supernatant was retained for cytokine determination.

Cytokine determination. Concentrations of IFN- $\gamma$, IL4, IL10 and IL12 in lung homogenate supernatants were determined by using ELISA kits (Nordic BioSite). Standard curves were constructed for IL4, range 7·8$500 \mathrm{pg} \mathrm{m}^{-1}$ (lower detection limit, $0.96 \mathrm{pg} \mathrm{m}^{-1}$ ); IFN- $\gamma, 40$ $5000 \mathrm{pg} \mathrm{m}^{-1}\left(10 \mathrm{pg} \mathrm{ml}^{-1}\right)$; IL10, $1 \cdot 2-80 \mathrm{pg} \mathrm{m}^{-1}\left(1 \mathrm{pg} \mathrm{ml}^{-1}\right)$; and IL12, 5-1000 $\mathrm{pg} \mathrm{ml}^{-1}\left(<5 \mathrm{pg} \mathrm{ml}^{-1}\right)$. Optical density of each sample was plotted on the standard curve of the respective cytokine ELISA plate to obtain cytokine concentrations.

Protease activity and alginate determination. Bacteria were incubated at $37^{\circ} \mathrm{C}$ in $\mathrm{LB}$ broth with rapid shaking for $18 \mathrm{~h}$. Cells were collected by centrifugation and LasB elastase activity was determined spectrophotometrically by using elastin-Congo red (Sigma) as substrate (Ohman et al., 1980). Protease activity was expressed as $A_{595}$ units $\min ^{-1}$ (g protein $)^{-1}$. Concentrations of alginate, expressed as $\mathrm{mg}$ ( 1 culture supernatant $)^{-1}$, were measured by the carbazole-borate method (Knutson \& Jeanes, 1968).

Statistical analysis. Data were analysed by using the statistical software package SPSS (version 10.0 for Windows; SPSS, Chicago, IL, USA; http://www.spss.com). Unpaired differences in continuous data were analysed by the Mann-Whitney U-test and categorical data were compared by using a $\chi$-squared test. Simple regression tests were used for correlation analysis between parameters.

\section{RESULTS AND DISCUSSION}

This study was undertaken to investigate the effect of alginate production on the virulence of three genetically defined $P$. aeruginosa strains in an animal model of acute infection. The prototypic non-mucoid strain PAO1 is capable of producing alginate (Holloway \& Morgan, 1986). The isogenic derivatives of this strain were $\mathrm{Alg}^{+} \mathrm{PAOmucA22}$ (PDO300), which is constitutive for alginate production (Mathee et al., 1999), and $\mathrm{Alg}^{-} \mathrm{PAO} a \lg D$, which has a mutation in the key alginate biosynthetic gene ( $\operatorname{alg} D$, which encodes GDP-mannose dehydrogenase), rendering it incapable of producing alginate (Garrett et al., 1999). These strains were instilled into mouse lungs to create acute infection; animals were killed 24 or $48 \mathrm{~h}$ post-infection.

\section{Alginate production results in severe lung pathology}

Twenty-four hours post-infection, pulmonary histopatho- logical changes in the PAO1 group were milder and less PMN infiltration was seen than in the other strains (Fig. 1). Significant pulmonary oedema with milder haemorrhage was seen in the $\mathrm{Alg}^{-} \mathrm{PAO} a \lg D$ group, but marked PMN infiltration was observed in the $\mathrm{Alg}^{+} \mathrm{PAOmucA22}$ group (Fig. 1). All three groups showed clear infiltration of PMNs in the lung foci at $48 \mathrm{~h}$ post-infection, although it was more profound in the $\mathrm{Alg}^{+} \mathrm{PAO}$ mucA22 group (Fig. 1).

Judging by the lung scoring, significantly milder changes in lung pathology were found in the PAO1 group $(P<0.05)$ at $24 \mathrm{~h}$ post-infection than in the $\mathrm{Alg}^{-} \mathrm{PAO}$ algD group (Table 1). LIMP analysis of all three groups at $24 \mathrm{~h}$ post-infection showed that the scores of the $\mathrm{Alg}^{-} \mathrm{PAO} a l g D$ and $\mathrm{Alg}^{+}$ $\mathrm{PAOmucA22}$ groups were significantly higher than the PAO1 group $(P \leqslant 0.001$ and $P \leqslant 0 \cdot 05$, respectively; Table 1$)$. Furthermore, the $\mathrm{Alg}^{-} \mathrm{PAO}$ algD group also had significantly higher LIMP scores than the $\mathrm{Alg}^{+} \mathrm{PAOmucA22}$ group $(P<0.05$; Table 1$)$. At $48 \mathrm{~h}$ post-infection, the lung pathology of the $\mathrm{Alg}^{+} \mathrm{PAOmucA2} 2$ group was significantly more severe than that of the PAO1 group $(P \leqslant 0 \cdot 02$, Table 1$)$. In the $\mathrm{Alg}^{-} \mathrm{PAO}$ algD group, LIMP score at $48 \mathrm{~h}$ post-infection was obviously lower than that at $24 \mathrm{~h}(P<0 \cdot 01)$.

Both micro- and macroscopic pathological analyses revealed that wild-type PAO1 infection resulted in the mildest pathology (Fig. 1). In terms of infective severity at $24 \mathrm{~h}$, the order of the strains was PAO1 $<\mathrm{Alg}^{+} \mathrm{PAO}$ mucA22 $<\mathrm{Alg}^{-}$ $\mathrm{PAO} a \lg D$, whereas at $48 \mathrm{~h}$ post-infection it was $\mathrm{PAO} / \mathrm{Alg}^{-}$ $\mathrm{PAO} a l g D<\mathrm{Alg}^{+} \mathrm{PAOmucA22}$. Of the three strains used, only the $\mathrm{Alg}^{+}$strain produced copious amounts of alginate [255 mg (l culture supernatant $)^{-1}$ ]. No alginate was detected in broth culture supernatants of the non-mucoid strains. Alginate production has been inversely correlated with protease activity (Mohr et al., 1990); elastase activity in $\mathrm{Alg}^{+}$ PAOmucA22 (17.8 U) was reduced approximately four- and sixfold compared to its parent strain (PAO1; 69.6 U) and $\mathrm{Alg}^{-} \mathrm{PAO}$ algD (107.9 U), respectively. The $\mathrm{Alg}^{-} \mathrm{PAO} a \lg D$ strain produced $1 \cdot 5$-fold more elastase than PAO1. The severity of $\mathrm{Alg}^{-} \mathrm{PAOalgD}$ at $24 \mathrm{~h}$ post-infection may be explained by the ability of this strain to produce higher amounts of elastase.

Similarly, in another study that used a neutropenic mouse model of fatal $P$. aeruginosa sepsis, the authors concluded that loss of ability to make alginate (inactivation of $a \lg T / U$ ) resulted in increased virulence (Yu et al., 1996). They did not observe any differences in $\mathrm{LD}_{50}$ between wild-type $\mathrm{PAO} 1$ and the algT/U:: $\mathrm{Tc}^{\mathrm{R}}$ mutant. However, the null mutant showed a reduced mean time of death in two of the animal strains tested: the normal C57BL/6 mouse and the endotoxinresistant C3H/HeJ mouse (Yu et al., 1996). Although it appeared initially that the loss of alginate production resulted in increased virulence, it was temporary. At $48 \mathrm{~h}$ postinfection, we did not observe any difference between the non-mucoid strains.

Despite significant PMN infiltration in the lung foci at $48 \mathrm{~h}$ post-infection in $\mathrm{Alg}^{+} \mathrm{PAOmucA22}$-infected lungs, this did not appear to influence bacterial clearance. This supports in 

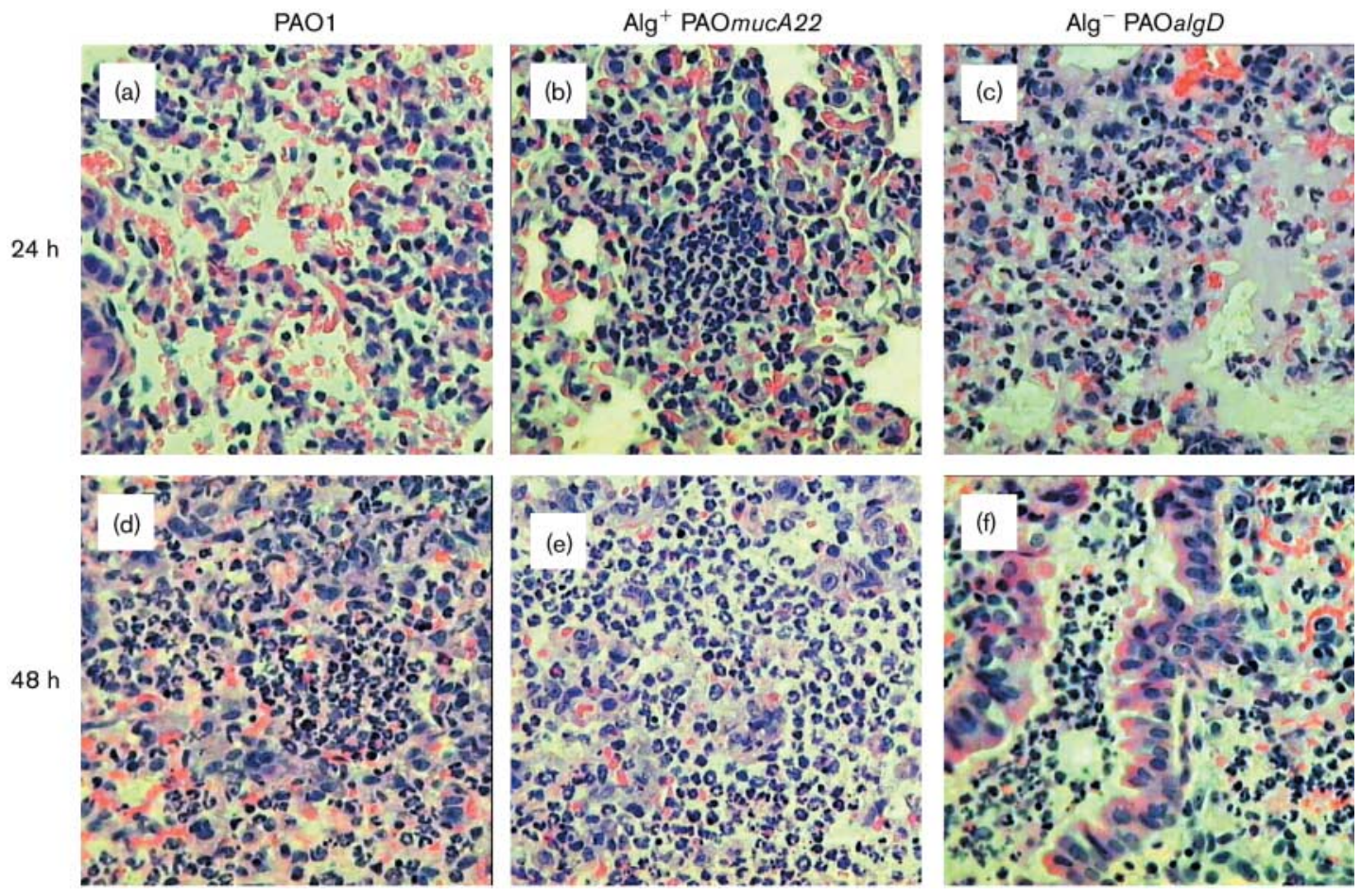

Fig. 1. Lung histopathology showing inflammatory response against $P$. aeruginosa (magnification, $\times 250$ ). Panels (a), (b) and (c) show pathology at $24 \mathrm{~h}$ post-infection; panels (d), (e) and ( $\mathrm{f})$, at $48 \mathrm{~h}$ post-infection. Panels (a) and (d): PAO1 strain shows less PMN infiltration and milder lung haemorrhage at $24 \mathrm{~h}$ and increased PMN infiltration at $48 \mathrm{~h}$ post-infection. Panels (b) and (e) ( $\mathrm{Alg}^{+} \mathrm{PAO}$ mucA22) show significant PMN infiltration at $24 \mathrm{~h} \mathrm{(b)} \mathrm{and} 48 \mathrm{~h} \mathrm{(e)} \mathrm{post-infection.} \mathrm{Panels} \mathrm{(c)} \mathrm{and} \mathrm{(f)} \mathrm{(Alg}{ }^{-}$PAOalgD) show PMN infiltration, milder lung haemorrhage and significant lung oedema at $24 \mathrm{~h}$ (c) and extensive PMN infiltration in both bronchi and lung tissues at $48 \mathrm{~h}$ (f) post-infection.

(a)

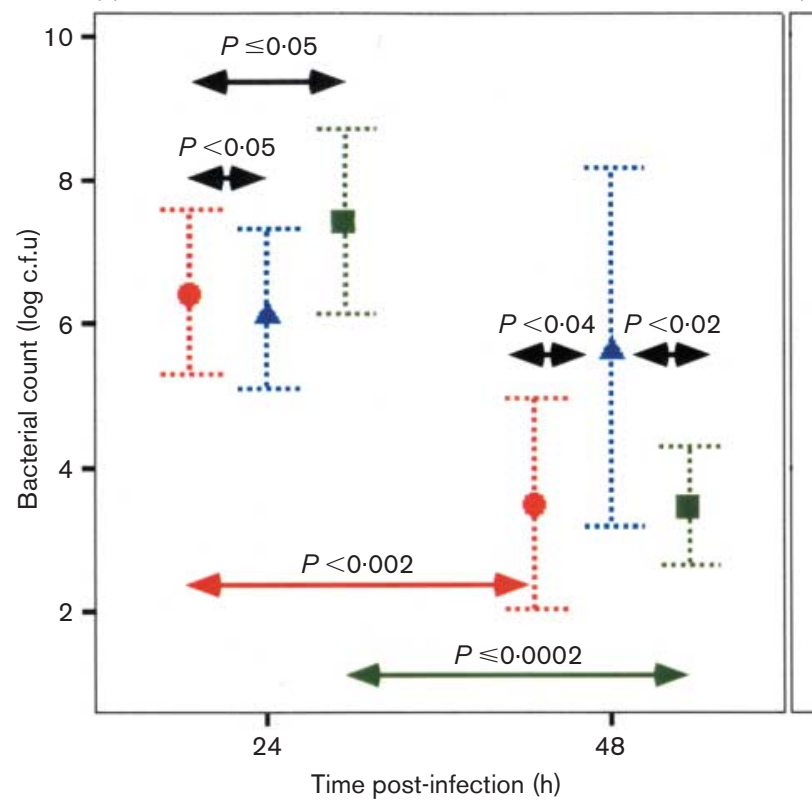

(b)

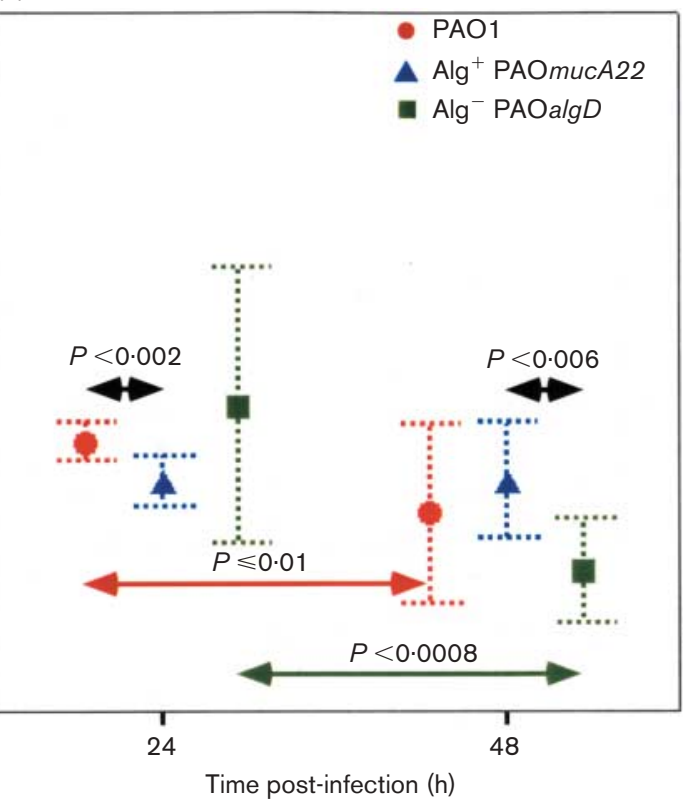

Fig. 2. Lung (a) and spleen (b) bacteriology: bacterial count (c.f.u.) from homogenized lung and spleen tissues from the PAO1 ( $)$ ), $A l g-P A O a l g D$ $(\mathbf{\square})$ and $\mathrm{Alg}^{+}$PAOmucA22 ( $\left.\mathbf{\Delta}\right)$ groups. Thirteen animals per bacterial strain were used. 
Table 1. Lung pathology analysis

\begin{tabular}{|c|c|c|c|c|c|}
\hline Strain & & LIMP $^{\star}$ & $P$ value $\neq$ & Lung score ${ }^{\star}$ & $P$ value $\neq$ \\
\hline Wild-type PAO1 & $48 \mathrm{~h}$ & $0 \cdot 40(0 \cdot 15-0 \cdot 52)$ & & $4 \cdot 00(3 \cdot 00-4 \cdot 00)$ & \\
\hline \multirow[t]{2}{*}{$\mathrm{Alg}^{+} \mathrm{PAOmucA22}$} & $24 \mathrm{~h}$ & $0 \cdot 50(0 \cdot 25-0 \cdot 62)$ & $<0 \cdot 05(\mathrm{PAO} 1)$ & $4 \cdot 00(3 \cdot 00-4 \cdot 00)$ & \\
\hline & $48 \mathrm{~h}$ & $0 \cdot 50(0 \cdot 40-0 \cdot 80)$ & $<0 \cdot 02(\mathrm{PAO} 1)$ & $4 \cdot 00(4 \cdot 00-4 \cdot 00)$ & \\
\hline \multirow{2}{*}{$\mathrm{Alg}^{-} \mathrm{PAO} a l g D$} & $48 \mathrm{~h}$ & $0 \cdot 49(0 \cdot 26-0 \cdot 51)$ & & $4 \cdot 00(3 \cdot 00-4 \cdot 00)$ & \\
\hline & $P$ value $\dagger$ & $<0 \cdot 002$ & & & \\
\hline
\end{tabular}

*Thirteen animals per bacterial strain were used; values are medians with range in parentheses.

$\dagger$ Significant $P$ values between 24 and 48 h analysis.

$\ddagger$ Significant values compared to strain groups indicated in parentheses; PAO1 and mucA refer to wild-type PAO1 and Alg ${ }^{+} \mathrm{PAOmucA22}$, respectively.

vitro studies that demonstrated that alginate protected bacteria from phagocytosis, opsonization, antibodies, complement and PMN infiltration (Laharrague et al., 1984; Oliver \& Weir, 1985; Eftekhar \& Speert, 1988; Krieg et al., 1988; Stiver et al., 1988; Jensen et al., 1990; Pedersen et al., 1990; Mathee et al., 1999). Conversion of bacteria to the nontractable, alginate-producing phenotype is partly due to PMN infiltration (Mathee et al., 1999). Alginate has been demonstrated to interfere with PMN functions such as adherence, oxygen metabolism, degranulation and bactericidal activity (Pedersen et al., 1990; Mai et al., 1993). At the molecular level, alginate also alters the signal transduction pathway by modulating PMN protein kinase $\mathrm{C}$ and G-protein activity (König et al., 1992).

Excessive infiltration of PMNs contributes to lung tissue damage, due to the release of reactive oxygen species, and the severity of histopathological changes correlates with the ability of the bacteria to persist in the lung and evade host clearance. We observed a positive correlation $(r=0.66)$ between quantitative lung bacteriology and score of lung pathology in the $\mathrm{Alg}^{+} \mathrm{PAOmucA22}$ group at $24 \mathrm{~h}$ postinfection (Table 2). Thus, alginate production not only impedes pulmonary clearance, but also results in severe tissue damage. This is reminiscent of a late-stage chronic infection that exhibits marked local destruction of lung tissues of CF patients with $\mathrm{Alg}^{+} P$. aeruginosa strains; for some such patients, lung transplantation is the only hope for survival (Pedersen et al., 1990).

\section{Alginate production and bacterial persistence in the lung}

Persistence of invading bacteria and ability of the host immune system to clear bacteria can be inferred from lung bacteriology. At $24 \mathrm{~h}$ post-infection, significantly higher bacterial counts were found in the $\mathrm{Alg}^{-} \mathrm{PAO}$ algD group than in the PAO1 $(P \leqslant 0.05)$ and the $\operatorname{Alg}^{+}$PAOmucA22
$(P \leqslant 0.05)$ groups (Fig. 2). Bacterial load at $48 \mathrm{~h}$ postinfection in the $\mathrm{Alg}^{+} \mathrm{PAO}$ mucA22 group was 57 -fold higher than that in the $\operatorname{Alg}^{-} \mathrm{PAOalgD}$ group $(P<0.02)$ and 158 times higher than that in the PAO1 group $(P<0 \cdot 04)$ (Fig. 2$)$. Comparing the 24 and $48 \mathrm{~h}$ time-points, the wild-type PAO1 and $\mathrm{Alg}^{-} \mathrm{PAO} a \mathrm{lg} D$ groups showed significantly reduced bacterial loads $(P<0.002$ and $P=0.0002$, respectively), but there was no significant change in the $\mathrm{Alg}^{+} \mathrm{PAOmucA22}$ group $(P>0.4)$ (Fig. 2).

The order of these three strains in terms of their lung bacterial load at $24 \mathrm{~h}$ post-infection was $\mathrm{Alg}^{+} \mathrm{PAOmucA2} 2$ $<\mathrm{PAO} 1<\mathrm{Alg}^{-} \mathrm{PAO} a l g D$, and at $48 \mathrm{~h}$ post-infection it was $\mathrm{PAO} 1<\mathrm{Alg}^{-} \mathrm{PAO} a l g D<\mathrm{Alg}^{+} \mathrm{PAOmucA} 22$ (Table 1). At 24 -h post-infection, the $\mathrm{Alg}^{-} \mathrm{PAO} \operatorname{alg} D$ group had the highest bacterial load; however, at $48 \mathrm{~h}$ post-infection, the $\mathrm{Alg}^{+} \mathrm{PAOmucA22}$ strain prevailed, suggesting significant microbial protection that was probably due to the overproduction of alginate. These data contradict an earlier reported animal study that used guinea pigs, which concluded that the mucoid phenotype had no selective effect to impede pulmonary clearing (Blackwood \& Pennington, 1981). The negative control non-mucoid strain used in the guinea pig study was isolated by repeated passages of the mucoid CF strain that is likely to have a defective mucA allele, encoding the anti-sigma factor (Martin et al., 1993; Boucher et al., 1997). Based on our current understanding of alginate genes, it is likely that these non-mucoid strains have second site suppressor mutations, possibly in alg $T / U$, which encodes the sigma factor (DeVries \& Ohman, 1994; Schurr et al., 1994). The use of two strains with undefined mutations may have affected the outcome of their experiment.

The most detailed study to date looked at the effect of alginate on bacterial clearance by using an aerosol infection model in which C57BL/6J, BALB/c and DBA/2Nhsd mice (Boucher et al., 1997) were infected with P. aeruginosa PAO381 (Fyfe \& Govan, 1980) and its derivatives, PAO578I (mucA22), 
Table 2. Correlation analysis with various parameters

\begin{tabular}{|c|c|c|c|c|}
\hline Parameter & Time (h) & Wild-type PAO1 & $\mathrm{Alg}^{+}$PAOmucA22 & $\mathrm{Alg}^{-} \mathrm{PAOalgD}$ \\
\hline \multicolumn{5}{|l|}{ Lung bacteriology } \\
\hline Spleen bacteriology & 24 & & & $r=0.75, P=0.01$ \\
\hline LIMP & 24 & & $r=0.66, P<0.04$ & \\
\hline \multicolumn{5}{|l|}{ IL4 } \\
\hline \multirow[t]{2}{*}{ Lung bacteriology } & 24 & & & $r=-0.63, P=0.05$ \\
\hline & 48 & $r=-0.72, P<0.02$ & & \\
\hline Lung score & 48 & $r=0.72, P<0.02$ & & \\
\hline \multicolumn{5}{|l|}{ IL10 } \\
\hline Lung score & 24 & & & $r=-0.68, P<0.032$ \\
\hline \multirow[t]{2}{*}{ IFN- $\gamma$} & 24 & $r=0.97, P=0.0001$ & $r=0.64, P<0.05$ & \\
\hline & 48 & $r=0.86, P<0.002$ & & $r=0.76, P=0.01$ \\
\hline Spleen bacteriology & 24 & & $r=0.83, P<0.003$ & \\
\hline
\end{tabular}

PAO578II (mucA22, sup-2; salt-dependent $\mathrm{Alg}^{+}$phenotype) and PAO578IIalgD:: Gm (Martin et al., 1993; Boucher et al., 1997). In this $4 \mathrm{~h}$ post-infection study, the alginateproducing strain had greater survival in the lungs than the parent strain and its algD mutant (Boucher et al., 1997). Similar results were observed in a repeated aerosol exposure study on C57BL/6J mice that used PAO381 and PAO578I (Yu et al., 1998). Although the experimental strains and animal infection models used here are different, the parallels in our conclusions are clear: alginate production promotes bacterial survival and persistence in lung infection.

\section{Alginate production and persistence in the spleen}

The presence of bacteria in the spleen reflects the ability of invading bacteria to spread from the initial point of inoculation. At $24 \mathrm{~h}$ post-infection, the spleen bacterial count for the $\mathrm{Alg}^{+} \mathrm{PAOmucA22}$ group was significantly lower than that for the PAO1 group $(P<0.002)$ (Fig. 2). However, at $48 \mathrm{~h}$ post-infection, higher counts were found for the $\mathrm{Alg}^{+} \mathrm{PAOmucA} 22$ group than for the $\mathrm{Alg}^{-} \mathrm{PAO} a \lg \mathrm{D}$ group $(P<0 \cdot 006)$, with bacterial counts approximately $5 \cdot 6$ and 40-fold higher for the groups with the non-mucoid strains $\mathrm{PAO} 1$ and $\mathrm{Alg}^{-} \mathrm{PAO} a \lg D$, respectively. Comparing the two time points at 24 and $48 \mathrm{~h}$ post-infection, significant differences were found for the PAO1 group $(P=0 \cdot 01$, Fig. 2$)$ and the $\mathrm{Alg}^{-} \mathrm{PAO} a \mathrm{lg} D$ group $(P<0.0008)$, but no significant difference was confirmed for the mucoid $\mathrm{Alg}^{+}$ PAOmucA22 group $(P>0 \cdot 6)$, indicating that the $\mathrm{Alg}^{+}$strain is more resistant to immune clearance associated with its mucoid phenotype (Fig. 2).

The order of strains in terms of spleen bacterial load at
$24 \mathrm{~h}$ post-infection was $\mathrm{Alg}^{+} \mathrm{PAOmucA} 22<\mathrm{PAO} 1 / \mathrm{Alg}^{-}$ $\mathrm{PAO} a l g D$; whereas at $48 \mathrm{~h}$, it was $\mathrm{PAO} 1 / \mathrm{Alg}^{-} \mathrm{PAO} a l g D<$ $\mathrm{Alg}^{+} \mathrm{PAOmucA22}$ (Fig. 2). Each strain produced significant septicaemia, but at $24 \mathrm{~h}$ post-infection, a significantly lower spleen bacterial count for the $\mathrm{Alg}^{+} \mathrm{PAOmucA22}$ group compared to the parent stain was evident. This difference may be partly associated with the reduced motility of the strain, compared to the non-mucoid strain PAO1 (data not shown). In addition, alginate production has been negatively correlated with synthesis of flagella, which may reduce the number of bacteria entering the bloodstream (Garrett et al., 1999). At $24 \mathrm{~h}$ post-infection, a positive correlation $(r=$ $0 \cdot 75)$ between lung and spleen bacteriology was evident for the $\mathrm{Alg}^{-} \mathrm{PAO} a \lg D$ group (Table 2). Both the PAO1 $(r=1.00)$ and $\mathrm{Alg}^{-} \mathrm{PAOalgD}(r=0.99)$ groups showed positive correlation at $48 \mathrm{~h}$ post-infection, whereas no significant correlation was seen in the $\mathrm{Alg}^{+} \mathrm{PAOmucA} 22$ group. The lower spleen bacterial count in the non-mucoid groups at $48 \mathrm{~h}$ post-infection suggests that the host was able to clear these non-mucoid organisms more efficiently than $\mathrm{Alg}^{+}$ PAOmucA22.

\section{Th1 cytokines are up-regulated at $48 \mathrm{~h}$ post- infection}

The immune response is modulated by $\mathrm{T}$ helper cells via changes in cytokine levels. In the present study, at 24 and $48 \mathrm{~h}$ post-infection, no significant differences were found in IFN$\gamma$, IL4, IL10 or IL12 between the three infection groups (Table $3)$. However, a comparison of the 24 and $48 \mathrm{~h}$ post-infection data indicated a significant increase in IFN- $\gamma$ and decrease in IL10 in all three groups (Table 3 ). Higher IL12 production, however, was detected in the PAO1 group compared to the 


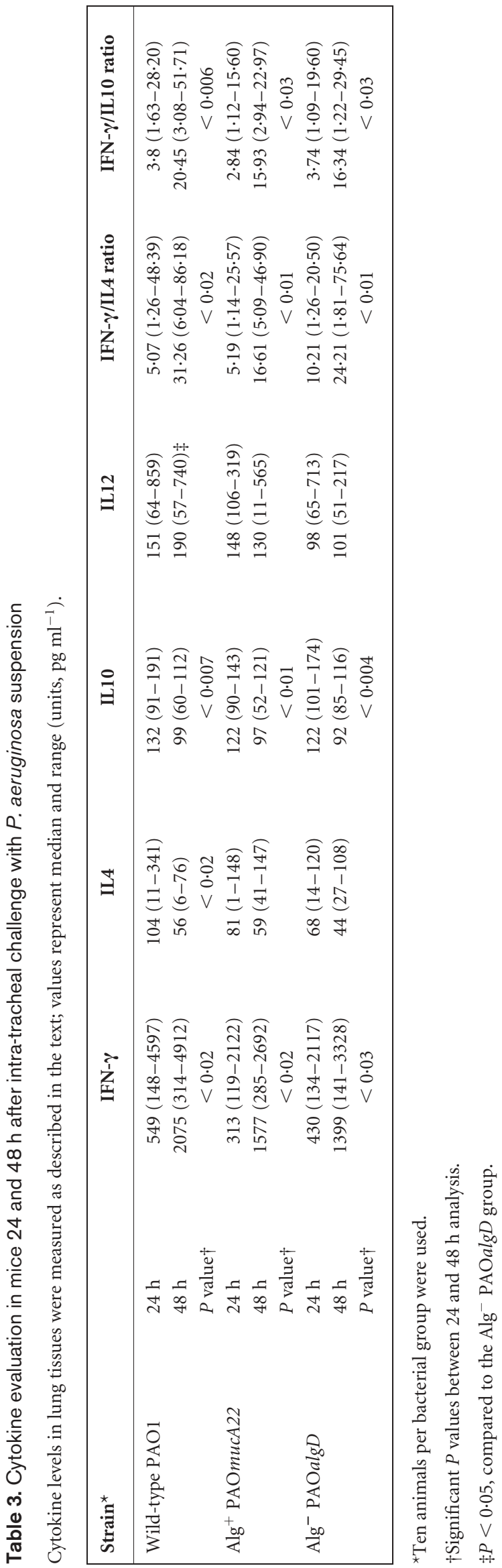

$\mathrm{Alg}^{-} \mathrm{PAO}$ algD group at $48 \mathrm{~h}$ post-infection $(P<0.05$; Table $3)$. Significant reduction of IL4 levels was seen only in the PAO1 group $(P<0.02$; Table 3$)$ at $48 \mathrm{~h}$ post-infection.

Positive correlations between IFN- $\gamma$ and IL12 were found in the PAO1 $(r=0.97, P<0.0001)$ and $\mathrm{Alg}^{+} \mathrm{PAOmucA22}$ $(r=0.64, P<0.05)$ groups at $24 \mathrm{~h}$ post-infection, and in the PAO1 $(r=0.86, P<0.002)$ and $\mathrm{Alg}^{-} \mathrm{PAOalgD}(r=0.76$, $P=0.01$ ) groups at $48 \mathrm{~h}$ post-infection (Table 2). This was not unexpected, as both of these cytokines are Th1 indicators. IL12 stimulates production of IFN- $\gamma$ by NK and T cells (Belardelli, 1995). The increase of IFN- $\gamma$ and decrease of IL10 in lung tissues that were seen at $48 \mathrm{~h}$ post-infection, compared to the results at $24 \mathrm{~h}$ post-infection, are predicted as IL10, if produced, suppresses the synthesis of proinflammatory cytokines by inhibiting IL12 and IFN- $\gamma$ production (Belardelli, 1995). In addition, levels of the pleiotropic cytokine IL4, a product of Th2 lymphocytes that inhibits the differentiation of Th1 cells (Hart et al., 1989; Belardelli, 1995), were also reduced in all three bacterial groups at $48 \mathrm{~h}$ post-infection, even though this difference was not statistically significant. These results suggest that the immune response to acute infection with $P$. aeruginosa at $48 \mathrm{~h}$ post-infection was predominantly a Th1-type response, compared to the results at $24 \mathrm{~h}$ post-infection. This was further demonstrated by analysing the ratios of IFN- $\gamma /$ IL4 and IFN- $\gamma /$ IL10 in all three groups. These ratios can be used as an indicator of Th1 versus Th2 responses; a higher ratio is an indicator of a Th1-dominated response and a lower ratio suggests a Th2-dominated response. The significant increase in these ratios between the 24 and $48 \mathrm{~h}$ time-points is indicative of a Th1-based immune response (Table 3). The immune response in CF patients with chronic $P$. aeruginosa infections is predominantly a Th2 response and is correlated with a poor prognosis (Moser et al., 2000). It has been proposed that shifting the immune response to Th1 may help to combat P. aeruginosa infection (Høiby et al., 2001). However, our results suggest that although the animals mount a Th1 response, it is not sufficient to alleviate mucoid $P$. aeruginosa infection.

\section{Diagnostic value of IL4 levels}

Early intermittent colonization of CF-affected lungs by nonmucoid $P$. aeruginosa, often treatable with minimal clinical symptoms, precedes obdurate chronic infection with mucoid variants. In our study, infection by the prototypic, nonmucoid strain PAO1 exhibited the mildest pathology and was cleared more quickly than the other strains. A negative correlation was found between the level of IL4 and lung $(r=-0.72, P<0.02)$ and spleen $(r=-0.71, P=0.02)$ bacteriology in the PAO1 group at $48 \mathrm{~h}$ post-infection. IL4 levels were positively correlated with lung pathological scoring in the PAO1 group at $48 \mathrm{~h}$ post-infection $(r=0.72$, $P<0.02)$. In addition, the $\mathrm{Alg}^{-} \mathrm{PAO}$ algD group showed a negative correlation between IL4 levels and lung $(r=-0 \cdot 63$, $P=0.05)$ and spleen $(r=-0.67, P<0.04)$ bacteriology at $24 \mathrm{~h}$ post-infection (Table 2). It appears that the immune response mounted was successful in lowering bacterial load, 
but the inflammatory defence mechanisms did lead to tissue damage. It is possible that the outcome in the non-mucoid groups was determined by the significant reduction in IL4 levels and relatively higher IFN- $\gamma$ levels. However, Jain-Vora et al. (1998) reported enhanced pulmonary clearance of $P$. aeruginosa in acute infection in transgenic mice by IL4. Thus, the role of IL4 levels in infection remains unclear with nonmucoid $P$. aeruginosa.

\section{Severity of infection is correlated with the imbalance between pro- and anti-inflammatory cytokine levels}

The $\mathrm{Alg}^{-} \mathrm{PAO}$ algD group had the highest bacterial load, the most severe pathology and showed a negative correlation between lung scores and IL10 levels $(r=-0.68, P<0.032)$ and a positive correlation between IL12 levels and LIMP $(r=0 \cdot 8, P<0.006)$ at $24 \mathrm{~h}$ post-infection. At $48 \mathrm{~h}$ postinfection, the $\mathrm{Alg}^{+} \mathrm{PAOmucA2} 2$ strain prevailed, suggesting significant microbial protection that is probably due to overproduction of alginate. The severity of lung pathology and PMN infiltration in the $\mathrm{Alg}^{+} \mathrm{PAO}$ mucA22 group may be due to an increase in pro-inflammatory cytokines IL12 and IFN $-\gamma$. This is supported by positive correlations between IL12 levels and lung pathology $(r=0.83, P<0.003)$ and between IL12 and IFN- $\gamma$ levels $(r=0.64, P<0.05)$, and negative correlations between IL10 levels and bacterial counts in the lung $(r=-0.78, P<0.009)$ and spleen $(r=-0.7, P<0.025)$ for the $\mathrm{Alg}^{+}$PAOmucA22 group at $48 \mathrm{~h}$ post-infection (Table 2 ).

The imbalance of pro- versus anti-inflammatory cytokines and the correlation with the severity of infection are similar to those reported in CF patients (Kronborg et al., 1993). It has been shown that bronchoalveolar lavage fluid of CF patients with chronic infection by mucoid strains has significantly lower levels of IL10 (Bonfield et al., 1995b). These authors further demonstrated that normal epithelial cells produce IL10 constitutively, but epithelial cells from chronically infected CF patients are defective for production of IL10 (Bonfield et al., 1995a). The IL10 knockout mice studies of Yu et al. (1998) provided supportive evidence for the role of IL10 in CF infection: following repeated aerosol exposure, they observed higher mortality and severe lung pathology in the IL10-deficient mice compared to controls ( $\mathrm{Yu}$ et al., 1998). In another study, using a chronic endobronchial infection by $P$. aeruginosa, it was demonstrated that IL10 knockout mice had severe weight loss and an increased area of lung inflammation, but no alterations in bacterial burden, compared to wild-type mice (Chmiel et al., 1999, 2002). Interestingly, in the current study, no correlation was seen between the PAO1 group and IL10 levels. This is in agreement with Noah et al. (1997), who showed that bronchoalveolar lavage fluid of young CF patients, whose early onset of infection was caused by non-mucoid $P$. aeruginosa, had normal levels of IL10.

Constitutive production of IL10 may help to prevent local tissue destruction by pro-inflammatory cytokines (Moore et al., 1993). It is possible that severity of lung pathology could be reduced by increasing IL10 levels, which would suppress synthesis of the pro-inflammatory cytokines IL12 and IFN- $\gamma$ (Belardelli, 1995). This idea is also supported by studies in which IL10 treatment increased the survival rate of mice infected with $P$. aeruginosa. The treatment enhanced bacterial clearance (Sawa et al., 1997; Matsumoto et al., 1998), improved survival, lessened severe weight loss, lowered the number of bronchoalveolar lavage neutrophils and decreased the area of lung inflammation (Chmiel et al., 1999, 2002).

Currently, most of the knowledge that concerns mucoid strains of $P$. aeruginosa, especially alginate production and its gene regulation, has been achieved from studies performed in vitro. Investigations in vivo are still quite limited and have focused on pulmonary clearance of the pathogen. As far as we know, the present study is the most comprehensive analysis to date of the role of alginate in the pathogenicity of $P$. aeruginosa, in terms of its bacterial survival in the lung and spleen and the host cytokine response during an early acute infection. Overproduction of alginate could be an important contributory factor for $\mathrm{Alg}^{+} \mathrm{PAO}$ mucA22 persistence and virulence. This study supports previous inferences that alginate is a virulence factor that contributes to bacterial adherence and persistence (Marcus \& Baker, 1985; Ramphal \& Pier, 1985; Doig et al., 1987), formation of microcolony and biofilm growth (Høiby, 1975; Lam et al., 1980; Pedersen, 1992), inhibition of PMN chemotaxis (Stiver et al., 1988; Pedersen et al., 1990), suppression of lymphocyte and PMN function (Pedersen et al., 1990; Mai et al., 1993), formation of a physical barrier to the immune system and antibiotics (Nichols et al., 1989; Evans et al., 1991; Hoyle \& Costerton, 1991; Mathee et al., 1994) and resistance to opsonic killing by PMNs and macrophages (Meshulam et al., 1984; Cabral et al., 1987; Jensen et al., 1990; Pedersen et al., 1992).

Patients with chronic infection should benefit from consistent use of anti-inflammatory treatment. However, to better understand the role of alginate in chronic infection and the host immune response, we need to look at the expression of pro- and anti-inflammatory cytokines at both the molecular and cellular levels. This will allow novel therapeutic measures against chronic $P$. aeruginosa infection in CF patients to be developed.

\section{ACKNOWLEDGEMENTS}

Expert technical assistance from Jette Pedersen in histopathology and from Tina Wassermann in determination of bacterial virulence factors is highly appreciated. We are grateful to Giri Narasimhan for help with analysis and Ophelia Weeks for the use of her microscope. We thank DeEtta Mills, Charles Bigger, Suriya Jayawardena and Laurie Richardson for critical reading of the manuscript. We are immensely grateful to the JMM editor for critical review of the manuscript. This work was supported by grants from the College of Arts and Sciences, Florida International University (K. M. and Z. S.), the Cystic Fibrosis Foundation (K. M. and Z. S.), the Danish Medical Research Council (K. M. and N. H.) and Dansk Dorge A/S, Copenhagen (A. K., K. M. and Z. S.). 


\section{REFERENCES}

Baltimore, R. S., Christie, C. D. \& Smith, G. J. (1989). Immunohistopathologic localization of Pseudomonas aeruginosa in lungs from patients with cystic fibrosis. Implications for the pathogenesis of progressive lung deterioration. Am Rev Respir Dis 140, 1650-1661.

Banchereau, J. (1995). Converging and diverging properties of human interleukin-4 and interleukin-10. Behring Inst Mitt 96, 58-77.

Belardelli, F. (1995). Role of interferons and other cytokines in the regulation of the immune response. Acta Pathol Microbiol Immunol Scand 103, 161-179.

Blackwood, L. L. \& Pennington, J. E. (1981). Influence of mucoid coating on clearance of Pseudomonas aeruginosa from lungs. Infect Immun 32, 443-448.

Bonfield, T. L., Konstan, M. W., Burfeind, P., Panuska, J. R., Hilliard, J. B. \& Berger, M. (1995a). Normal bronchial epithelial cells constitutively produce the anti-inflammatory cytokine interleukin-10, which is downregulated in cystic fibrosis. Am J Respir Cell Mol Biol 13, 257-261.

Bonfield, T. L., Panuska, J. R., Konstan, M. W., Hilliard, K. A., Hilliard, J. B., Ghnaim, H. \& Berger, M. (1995b). Inflammatory cytokines in cystic fibrosis lungs. Am J Respir Crit Care Med 152, 2111-2118.

Boucher, J. C., Yu, H., Mudd, M. H. \& Deretic, V. (1997). Mucoid Pseudomonas aeruginosa in cystic fibrosis: characterization of muc mutations in clinical isolates and analysis of clearance in a mouse model of respiratory infection. Infect Immun 65, 3838-3846.

Cabral, D. A., Loh, B. A. \& Speert, D. P. (1987). Mucoid Pseudomonas aeruginosa resists nonopsonic phagocytosis by human neutrophils and macrophages. Pediatr Res 22, 429-431.

Chmiel, J. F., Konstan, M. W., Knesebeck, J. E., Hilliard, J. B., Bonfield, T. L., Dawson, D. V. \& Berger, M. (1999). IL-10 attenuates excessive inflammation in chronic Pseudomonas infection in mice. Am J Respir Crit Care Med 160, 2040-2047.

Chmiel, J. F., Konstan, M. W., Saadane, A., Krenicky, J. E., Lester Kirchner, H. \& Berger, M. (2002). Prolonged inflammatory response to acute Pseudomonas challenge in interleukin-10 knockout mice. Am J Respir Crit Care Med 165, 1176-1181.

Davidson, I. W., Sutherland, I. W. \& Lawson, C. J. (1977). Localization of O-acetyl groups of bacterial alginate. J Gen Microbiol 98, 603-606.

DeVault, J. D., Kimbara, K. \& Chakrabarty, A. M. (1990). Pulmonary dehydration and infection in cystic fibrosis: evidence that ethanol activates alginate gene expression and induction of mucoidy in Pseudomonas aeruginosa. Mol Microbiol 4, 737-745.

DeVries, C. A. \& Ohman, D. E. (1994). Mucoid-to-nonmucoid conversion in alginate-producing Pseudomonas aeruginosa often results from spontaneous mutations in $\operatorname{alg} T$, encoding a putative alternate sigma factor, and shows evidence for autoregulation. J Bacteriol 176, 6677-6687.

Doig, P., Smith, N. R., Todd, T. \& Irvin, R. T. (1987). Characterization of the binding of Pseudomonas aeruginosa alginate to human epithelial cells. Infect Immun 55, 1517-1522.

Eftekhar, F. \& Speert, D. P. (1988). Alginase treatment of mucoid Pseudomonas aeruginosa enhances phagocytosis by human monocytederived macrophages. Infect Immun 56, 2788-2793.

Evans, L. R. \& Linker, A. (1973). Production and characterization of the slime polysaccharide of Pseudomonas aeruginosa. J Bacteriol 116, 915-924.

Evans, D. J., Allison, D. G., Brown, M. R. \& Gilbert, P. (1991). Susceptibility of Pseudomonas aeruginosa and Escherichia coli biofilms towards ciprofloxacin: effect of specific growth rate. J Antimicrob Chemother 27, 177-184.
Fyfe, J. A. M. \& Govan, J. R. W. (1980). Alginate synthesis in mucoid Pseudomonas aeruginosa: a chromosomal locus involved in control. J Gen Microbiol 119, 443-450.

Garrett, E. S., Perlegas, D. \& Wozniak, D. J. (1999). Negative control of flagellum synthesis in Pseudomonas aeruginosa is modulated by the alternative sigma factor AlgT (AlgU). J Bacteriol 181, 7401-7404.

Germann, T., Bongartz, M., Dlugonska, H. \& 7 other authors (1995). Interleukin-12 profoundly up-regulates the synthesis of antigen-specific complement-fixing IgG2a, IgG2b and IgG3 antibody subclasses in vivo. Eur J Immunol 25, 823-829.

Govan, J. R. W. \& Fyfe, J. A. M. (1978). Mucoid Pseudomonas aeruginosa and cystic fibrosis: resistance of the mucoid form to carbenicillin, flucloxacillin and tobramycin and the isolation of mucoid variants in vitro. J Antimicrob Chemother 4, 233-240.

Hart, P. H., Vitti, G. F., Burgess, D. R., Whitty, G. A., Piccoli, D. S. \& Hamilton, J. A. (1989). Potential antiinflammatory effects of interleukin 4: suppression of human monocyte tumor necrosis factor alpha, interleukin 1, and prostaglandin E2. Proc Natl Acad Sci U S A 86, 3803-3807.

Høiby, N. (1975). Prevalence of mucoid strains of Pseudomonas aeruginosa in bacteriological specimens from patients with cystic fibrosis and patients with other diseases. Acta Pathol Microbiol Scand Suppl 83, 549-552.

Høiby, N., Krogh Johansen, H., Moser, C., Song, Z., Ciofu, O. \& Kharazmi, A. (2001). Pseudomonas aeruginosa and the in vitro and in vivo biofilm mode of growth. Microbes Infect 3, 23-35.

Holloway, B. W. \& Morgan, A. F. (1986). Genome organization in Pseudomonas. Annu Rev Microbiol 40, 79-105.

Hoyle, B. D. \& Costerton, J. W. (1991). Bacterial resistance to antibiotics: the role of biofilms. Prog Drug Res 37, 91-105.

Hughes, K. T. \& Mathee, K. (1998). The anti-sigma factors. Annu Rev Microbiol 52, 231-286.

Jain-Vora, S., LeVine, A. M., Chroneos, Z., Ross, G. F., Hull, W. M. \& Whitsett, J. A. (1998). Interleukin-4 enhances pulmonary clearance of Pseudomonas aeruginosa. Infect Immun 66, 4229-4236.

Jensen, E. T., Kharazmi, A., Lam, K., Costerton, J. W. \& Høiby, N. (1990). Human polymorphonuclear leukocyte response to Pseudomonas aeruginosa grown in biofilms. Infect Immun 58, 2383-2385.

Johansen, H. K., Espersen, F., Pedersen, S. S., Hougen, H. P., Rygaard, J. \& Høiby, N. (1993). Chronic Pseudomonas aeruginosa lung infection in normal and athymic rats. Acta Pathol Microbiol Immunol Scand 101, 207-225.

Knutson, C. A. \& Jeanes, A. (1968). A new modification of the carbazole analysis: application to heteropolysaccharides. Anal Biochem 24, 470-481.

König, B., Friedl, P., Pedersen, S. S. \& König, W. (1992). Alginate - its role in neutrophil responses and signal transduction towards mucoid Pseudomonas aeruginosa bacteria. Int Arch Allergy Immunol 99, 98-106.

Krieg, D. P., Helmke, R. J., German, V. F. \& Mangos, J. A. (1988). Resistance of mucoid Pseudomonas aeruginosa to nonopsonic phagocytosis by alveolar macrophages in vitro. Infect Immun 56, 3173-3179.

Kronborg, G., Hansen, M. B., Svenson, M., Fomsgaard, A., Høiby, N. \& Bendtzen, K. (1993). Cytokines in sputum and serum from patients with cystic fibrosis and chronic Pseudomonas aeruginosa infection as markers of destructive inflammation in the lungs. Pediatr Pulmonol 15, 292-297.

Laharrague, P. F., Corberand, J. X., Fillola, G., Gleizes, B. J., Fontanilles, A. M. \& Gyrard, E. (1984). In vitro effect of the slime of Pseudomonas aeruginosa on the function of human polymorphonuclear neutrophils. Infect Immun 44, 760-762. 
Lam, J., Chan, R., Lam, K. \& Costerton, J. W. (1980). Production of mucoid microcolonies by Pseudomonas aeruginosa within infected lungs in cystic fibrosis. Infect Immun 28, 546-556.

Lyczak, J. B., Cannon, C. L. \& Pier, G. B. (2002). Lung infections associated with cystic fibrosis. Clin Microbiol Rev 15, 194-222.

Mai, G. T., Seow, W. K., Pier, G. B., McCormack, J. G. \& Thong, Y. H. (1993). Suppression of lymphocyte and neutrophil functions by Pseudomonas aeruginosa mucoid exopolysaccharide (alginate): reversal by physicochemical, alginase, and specific monoclonal antibody treatments. Infect Immun 61, 559-564.

Marcus, H. \& Baker, N. R. (1985). Quantitation of adherence of mucoid and nonmucoid Pseudomonas aeruginosa to hamster tracheal epithelium. Infect Immun 47, 723-729.

Martin, D. W., Schurr, M. J., Mudd, M. H., Govan, J. R. W., Holloway, B. W. \& Deretic, V. (1993). Mechanism of conversion to mucoidy in Pseudomonas aeruginosa infecting cystic fibrosis patients. Proc Natl Acad Sci U S A 90, 8377-8381.

Mathee, K., Ciofu, O., Sternberg, C. \& 9 other authors (1999). Mucoid conversion of Pseudomonas aeruginosa by hydrogen peroxide: a mechanism for virulence activation in the cystic fibrosis lung. Microbiology 145, 1349-1357.

Mathee, K., Kharazmi, A. \& Høiby, N. (2002). Role of exopolysaccharide in biofilm matrix formation, the alginate paradigm. In Molecular Ecology of Biofilms. Edited by R. J. C. McLean \& A. W. Decho. Wymondham, UK: Horizon.

Matsumoto, T., Tateda, K., Miyazaki, S., Furuya, N., Ohno, A., Ishii, Y., Hirakata, Y. \& Yamaguchi, K. (1998). Effect of interleukin-10 on gutderived sepsis caused by Pseudomonas aeruginosa in mice. Antimicrob Agents Chemother 42, 2853-2857.

Meshulam, T., Obedeanu, N., Merzbach, D. \& Sobel, J. D. (1984). Phagocytosis of mucoid and nonmucoid strains of Pseudomonas aeruginosa. Clin Immunol Immunopathol 32, 151-165.

Mohr, C. D., Rust, L., Albus, A. M., Iglewski, B. H. \& Deretic, V. (1990). Expression patterns of genes encoding elastase and controlling mucoidy: co-ordinate regulation of two virulence factors in Pseudomonas aeruginosa isolates from cystic fibrosis. Mol Microbiol 4, 2103-2110.

Moore, K. W., O'Garra, A., de Waal Malefyt, R., Vieira, P. \& Mosmann, T. R. (1993). Interleukin-10. Annu Rev Immunol 11, 165-190.

Moser, C., Johansen, H. K., Song, Z., Hougen, H. P., Rygaard, J. \& Høiby, N. (1997). Chronic Pseudomonas aeruginosa lung infection is more severe in Th2 responding BALB/c mice compared to Th1 responding $\mathrm{C} 3 \mathrm{H} / \mathrm{HeN}$ mice. Acta Pathol Microbiol Immunol Scand 105, 838-842.

Moser, C., Kjaergaard, S., Pressler, T., Kharazmi, A., Koch, C. \& Høiby, N. (2000). The immune response to chronic Pseudomonas aeruginosa lung infection in cystic fibrosis patients is predominantly of the Th2 type. Acta Pathol Microbiol Immunol Scand 108, 329-335.

Nichols, W. W., Evans, M. J., Slack, M. P. E. \& Walmsley, H. L. (1989). The penetration of antibiotics into aggregates of mucoid and non-mucoid Pseudomonas aeruginosa. J Gen Microbiol 135, 1291-1303.
Noah, T. L., Black, H. R., Cheng, P. W., Wood, R. E. \& Leigh, M. W. (1997), Nasal and bronchoalveolar lavage fluid cytokines in early cystic fibrosis. J Infect Dis 175, 638-647.

Ohman, D. E., Cryz, S. J. \& Iglewski, B. H. (1980). Isolation and characterization of a Pseudomonas aeruginosa $\mathrm{PAO}$ mutant that produces altered elastase. J Bacteriol 142, 836-842.

Oliver, A. M. \& Weir, D. M. (1985). The effect of Pseudomonas alginate on rat alveolar macrophage phagocytosis and bacterial opsonization. Clin Exp Immunol 59, 190-196.

Pedersen, S. S. (1992). Lung infection with alginate-producing, mucoid Pseudomonas aeruginosa in cystic fibrosis. Acta Pathol Microbiol Immunol Scand Suppl 28, 1-79.

Pedersen, S. S., Kharazmi, A., Espersen, F. \& Høiby, N. (1990). Pseudomonas aeruginosa alginate in cystic fibrosis sputum and the inflammatory response. Infect Immun 58, 3363-3368.

Pedersen, S. S., Høiby, N., Espersen, F. \& Koch, C. (1992). Role of alginate in infection with mucoid Pseudomonas aeruginosa in cystic fibrosis. Thorax 47, 6-13.

Ramphal, R. \& Pier, G. B. (1985). Role of Pseudomonas aeruginosa mucoid exopolysaccharide in adherence to tracheal cells. Infect Immun 47, 1-4.

Sawa, T., Corry, D. B., Gropper, M. A., Ohara, M., Kurahashi, K. \& Wiener-Kronish, J. P. (1997). IL-10 improves lung injury and survival in Pseudomonas aeruginosa pneumonia. J Immunol 159, 2858-2866.

Schurr, M. J., Martin, D. W., Mudd, M. H. \& Deretic, V. (1994). Gene cluster controlling conversion to alginate-overproducing phenotype in Pseudomonas aeruginosa: functional analysis in a heterologous host and role in the instability of mucoidy. J Bacteriol 176, 3375-3382.

Song, Z., Kharazmi, A., Wu, H., Faber, V., Moser, C., Krogh, H. K., Rygaard, J. \& Høiby, N. (1998). Effects of ginseng treatment on neutrophil chemiluminescence and immunoglobulin $\mathrm{G}$ subclasses in a rat model of chronic Pseudomonas aeruginosa pneumonia. Clin Diagn Lab Immunol 5, 882-887.

Stiver, H. G., Zachidniak, K. \& Speert, D. P. (1988). Inhibition of polymorphonuclear leukocyte chemotaxis by the mucoid exopolysaccharide of Pseudomonas aeruginosa. Clin Invest Med 11, 247-252.

Stotland, P. K., Radzioch, D. \& Stevenson, M. M. (2000). Mouse models of chronic lung infection with Pseudomonas aeruginosa: models for the study of cystic fibrosis. Pediatr Pulmonol 30, 413-424.

Terry, J. M., Pina, S. E. \& Mattingly, S. J. (1991). Environmental conditions which influence mucoid conversion in Pseudomonas aeruginosa PAO1. Infect Immun 59, 471-477.

Yu, H., Boucher, J. C, Hibler, N. S. \& Deretic, V. (1996). Virulence properties of Pseudomonas aeruginosa lacking the extreme-stress sigma factor AlgU (sigmaE). Infect Immun 64, 2774-2781.

Yu, H., Hanes, M., Chrisp, C. E., Boucher, J. C. \& Deretic, V. (1998). Microbial pathogenesis in cystic fibrosis: pulmonary clearance of mucoid Pseudomonas aeruginosa and inflammation in a mouse model of repeated respiratory challenge. Infect Immun 66, 280-288. 